DOI 10.37882/2223-2982.2021.10.26

\title{
ОСОБЕННОСТИ ИЗУЧЕНИЯ ЛЕКСИКИ АНГЛИЙСКОГО ЯЗЫКА С ПРИМЕНЕНИЕМ КОРПУСНОГО ПОДХОДА
}

\section{FEATURES OF STUDYING THE VOCABULARY \\ OF THE ENGLISH LANGUAGE USING THE CORPUS APPROACH}

\section{A. Nizameeva}

Summary: The article discusses the features of the use of corpus technologies of text analysis in the process of studying the vocabulary of the English language at school. The object of the study is the process of studying the vocabulary of the English language in a secondary school, the subject of the study is the corpus method and the specifics of its application in the aspect of the implementation of the process under consideration. The purpose of the article is to determine the current trends in the implementation of the corpus approach in the study of the vocabulary of the English language in the middle classes of a secondary school. The following methods were used in the research process: analysis, classification, comparison, generalization, synthesis, work with linguistic text corpora, etc.

In the process of working with theoretical sources, it was found that the new educational paradigm requires the search for new approaches in teaching foreign languages, one of which is «corpus technologies». The advantages of the corpus approach, from the point of view of modern linguodidactics, include: linguistic and statistical visibility; extensive search capabilities; efficiency of working with real language data. The peculiarity of the corpus approach is the possibility of an operational search for language material necessary for solving certain educational tasks in the process of teaching a foreign language.

According to the results of the study, among the priority tasks of teaching English vocabulary in middle classes, the effective solution of which becomes possible thanks to the use of the corpus approach, it is possible to distinguish: the expansion of the lexical vocabulary of students, the formation of skills for determining the lexical compatibility of words in order to overcome speech errors, the development of speech through the compilation of thematic lists of keywords. At the senior stage of training, it is possible for students to collectively compile their own text corpora, which allow them to clearly illustrate the features of the lexical meaning of a particular word. An interesting technique will be the use of a comparative analysis of English contexts of word usage and variants of the functioning of the word in the contexts of the Russian language.

Keywords: corpus linguistics, language corpus, concordance, linguistic technologies, vocabulary, word semantics, methods and techniques of teaching English, context.

\author{
Низамеева Альбина Марсилевна \\ К.п.н., дочент, Казанский филиал Российского \\ государственного университета правосудия, г. Казань \\ albina10091976@mail.ru
}

Аннотация: В статье рассматриваются особенности использования корпусных технологий анализа текста в процессе изучения лексики английского языка в школе. Объектом исследования является процесс изучения лексики английского языка в общеобразовательной школе, предмет исследования корпусный метод и специфика его применения в аспекте реализации рассматриваемого процесса. Цель статьи состоит в определении актуальных тенденций реализации корпусного подхода при изучении лексики английского языка в средних классах общеобразовательной школе. В процессе исследования использовались следующие методы: анализ, классификация, сравнение, обобщение, синтез, работа с лингвистическими корпусами текстов и т.д. В процессе работы с теоретическими источниками было установлено, что новая образовательная парадигма требует поиска новых подходов в обучении иностранным языкам, одними из которых являются «корпусные технологии». К преимуществам корпусного подхода, с точки зрения современной лингводидактики, относятся: лингвистическая и статистическая наглядность; широкие поисковые возможности; эффективность работы с реальными языковыми данными. Особенность корпусного подхода состоит в возможности оперативного поиска языкового материала, необходимого для решения тех или иных образовательных задач в процессе обучения иностранному языку. Согласно результатам исследования среди приоритетных задач обучения лексике английского языка в средних классах, эффективное решение которых становится возможным благодаря применению корпусного подхода, можно выделить: расширение лексического словаря учащихся, становление умений определения лексической сочетаемости слов с целью преодоления речевых ошибок, развитие речи посредством составления тематических списков ключевых слов. На старшей ступени обучения возможно коллективное составление учащимися собственных корпусов текстов, позволяющих наглядно проиллюстрировать особенности лексического значения того или иного слова. Интересным приемом будет использование сопоставительного анализа английских контекстов словоупотребления и вариантов функционирования слова в контекстах русского языка.

Ключевые слова: корпусная лингвистика, языковой корпус, конкорданс, лингвистические технологии, лексика, семантика слова, методы и приемы обучения английскому языку, контекст.

\section{Введение}

условиях новой социокультурной реальности, обусловленной процессами глобализации и информатизации XXI века, качественные изменения за- тронули всю отечественную систему образования в ее законодательном, содержательном и структурообразующем аспектах.

В соответствие с новыми образовательными стан- 
дартами, одними из ведущих требований к метапредметным результатам освоения основной общеобразовательной программы являются: готовность и способность к самостоятельной информационно-познавательной деятельности, умение ориентироваться в различных источниках информации, умение использовать средства информационных и коммуникационных технологий в решении когнитивных, коммуникативных и организационных задач [1].

Среди требований ФГОС к предметным результатам освоения базового курса иностранного языка особую значимость приобретают:

- формирование активного и пассивного словарей, обеспечивающих способность учащихся к активной коммуникации;

- становление культуры владения иностранным языком в соответствие с современными требованиями к устной и письменной речи [1].

Новая образовательная парадигма требует поиска новых подходов в обучении иностранным языкам, одними из которых являются «корпусные технологии» [3]. Особенность корпусного подхода состоит в возможности оперативного поиска языкового материала, необходимого для решения тех или иных образовательных задач в процессе обучения иностранному языку.

Исследование возможностей и перспектив корпусного подхода в обучении нашли отражение в работах зарубежных ученых: Ю. Бестгена, Д. Бибера, М. Льюиса, Д. Салазара, М. Скотта, С. Триббла, Н. Ханчиоглу и др. В отечественной науке интерес представляют труды О.Г. Гориной, И.Ю. Павловской, В.А. Плунгян, Е.П. Сосниной, П.В. Сысоева, А.Ю. Фильченко Н.Н. Шаламовой и др.

Цель настоящей статьи состоит в определении актуальных тенденций реализации корпусного подхода при изучении лексики английского языка в средних классах общеобразовательной школе.

В процессе работы использовались следующие методы исследования: анализ, классификация, сравнение, обобщение, синтез, работа с лингвистическими корпусами текстов и т.д.

Корпусный подход в изучении языков широко распространен в англоязычных странах и до сих пор не нашел должного применения на территории РФ. Как верно отметил В.А. Плунгян, «практики очень быстро оценили корпус как совершенно незаменимый инструмент: теперь для овладения языком человеку нужны не две, а три вещи: словарь, грамматика и корпус текстов данного языка. Потому что и словарь, и грамматика, в общем-то, бесполезны вне этого живого пространства, где язык, собственно, и функционирует» [6].

Появление корпусного подхода как лингводидактического метода в зарубежной образовательной практике обусловлено созданием в 60-е годы XX века первых лингвистических корпусов текстов, а также обретением корпусной лингвистикой статуса самостоятельной научной дисциплины. Как следствие, актуальные тенденции становления корпусного подхода в образовательной практике тесным образом связаны с теоретическим осмыслением особенностей корпусной лингвистики как науки.

В настоящее время существует множество определений понятия «корпусная лингвистика». В.П. Захаров и С.Ю. Богданова рассматривают дисциплину, как «раздел компьютерной лингвистики, занимающийся разработкой общих принципов построения и использования лингвистических корпусов (корпусов текстов) с применением компьютерных технологий» $[4$, с. 5]. По мнению исследователей, возможность признания корпусной лингвистики самостоятельной наукой обусловлена двумя значимыми факторами: характером используемого языкового материала и наличием собственного инструментария.

П.В. Сысоев в работе «Лингвистический корпус в методике обучения иностранным языкам» определяет корпусную лингвистику, как «раздел языкознания, занимающийся выявлением закономерностей функционирования языка через его анализ и изучение с помощью лингвистического корпуса» [9].

Одним из ведущих инструментов корпусной лингвистики является конкорданс, представляющий собой список всех употреблений слова в контексте со ссылками на источник [4, с. 5]. Другими словами, конкорданс позволяет найти необходимое слово в корпусе, выбирая фрагменты предложений, где оно употребляется в различных контекстах, что значительно повышает эффективность изучение различных оттенков семантики слова, его лексической сочетаемости.

Электронные корпусы предоставляют богатый лингвистический материал для учебных и исследовательских целей. В настоящее время в Internet представлено множество классических электронных корпусов на иностранных языках. Наиболее известные из них Британский и Американский национальный корпусы английского языка, немецкоязычные корпуса LIMAS, COSMAS. Из наиболее доступных для рядового пользователя-преподавателя иностранных языков являются Gutenberg Texts, British National Corpus Sampler, The Longman Corpus, LIMAS, корпусы новостей Рейтер, электронные архивы крупных газет (например, The Times). 
Что касается типологии корпусов текстов, то в прикладной лингвистике возможно использование таких типов как:

- исследовательские - ориентированы на анализ различных аспектов функционирования языковой системы;

- иллюстративные - содержат наглядное подтверждение лингвистических фактов;

- мониторные - предназначены для изучения языкового материала в диахроническом аспекте, а также контент-анализа;

- стилистические - направлены на изучение особенностей художественной манеры писателей;

- мультимедийные - содержащие аудио- визуальное сопровождение текста [8].

Одной из важных особенностей метода анализа на базе корпусов текстов является исследование не только чисто лингвистических явлений (грамматических или лексических функций слов, их связей с другими лексемами), но и таких явлений, как, например, частотности лексем или грамматических конструкций в тех или иных жанрах, диалектах.

В зарубежной лингводидактической практике в настоящее время можно выделить две актуальные тенденции реализации корпусного подхода в обучении:

1. Первое направление связано с качественным изменением принципов отбора языкового материала с целью составления лингвистических словарей и учебных материалов. Ни один издатель учебной продукции для изучения самых распространенных языков уже не может обойтись без корпусных данных, что привело к формированию нового стандарта для учебников по языку, который обозначается пометой «corpus-informed» на обложках таких изданий.

2. В аспекте второго направления ведется активный поиск эффективных приемов и форм работы по использованию корпусного подхода в процессе обучения родному и иностранным языкам $[12,13.14]$.

Особенно эффективен корпусный подход в изучении лексики иностранных языков. Носитель языка на подсознательном уровне различает оттенки значения слова, особенности сочетания с другими словами, при изучении иностранных языков употребление слов требует овладения множеством связей, которое становится возможным только при знакомстве с различными контекстами, доступными в рамках корпусной лингвистики.

Корпусный подход тесно связан с проблемным обучением и гарантирует появление интереса у школьников, так как они становятся своего рода «первооткрывателями» неизвестных им лингвистических явлений иностран- ного языка. К преимуществам корпусного подхода, с точки зрения современной лингводидактики, относятся:

- лингвистическая и статистическая наглядность;

- широкие поисковые возможности;

- эффективность работы с языковыми данными [6, с. 132].

Несмотря на результативность использования корпусного подхода в процессе обучения лексике английского языка, в отечественной образовательной практике работа с корпусами текстов встречается достаточно редко, что обусловлено недостаточной методической оснащенностью образовательного процесса (отсутствием специально разработанных лингводидактических материалов, свободного доступа к Интернет-ресурсам и т.д.).

Как следствие, современная методика обучения иностранному языку должна ориентироваться на последние достижения в сфере компьютерных технологий и корпусной лингвистики, как эффективных средств приобщения школьников к живому богатству иностранного языка. Как отмечает Е.П. Соснина, метод лингвистического исследования по корпусам обладает следующими важными характеристиками:

1. основывается на эмпирическом исследовании и изучает реальное употребление слов в живом пространстве языка;

2. включает значительную по содержательному объему репрезентативную коллекцию текстов;

3. предполагает работу в автоматическом и интерактивном режимах;

4. использует методы качественного и статистического анализа текстов;

5. является целевым, т.е. должен быть ориентирован на реальное приложение и результаты [8].

Следует отметить, что корпусный подход является эффективным методом овладения лексикой английского языка на всех ступенях обучения. При этом работа с компьютером и корпусами текстов требует некоторой подготовки. Как следствие, в начальной и средней школе методисты рекомендуют использовать карточки с отобранными преподавателем примерами употребления слова в различных контекстах, доступных восприятию и пониманию учащихся.

В аспекте изучения лексики английского языка в средних классах рекомендуется использовать корпусный подход для решения следующих образовательных задач:

1) Расширение активного словаря учащихся.

Задание: изучить данные конкорданса и определить 
значение слова 'incredible'.

1. Skates were tied on the wrong feet; some boys were trying to remember when they had last changed their socks; the smell was incredible.

2. The day after those comments, Robert Dole, the Republican leader in the Senate, branded them as 'incredible'.

3. And so, however unwillingly, and before I return to the dark-haired girl in the coffee bar, I feel obliged to describe now an almost incredible tale about my former friend Robert.

4. You can turn them up to the most incredible volume and strum them very lightly, and you get a really lovely sound.

5. Finally, second place in Hungary clinched the title for Mansell - with an incredible five races still to run.

6. I find that quite incredible.'

7. Well it's just so incredible that this oil has never been I mean nobody focused on it did they?

Из примера видно, что в контексте слово 'incredible' переводиться как «невероятно» или «невероятный». Подобное задание может быть использовано для изучения новой лексики, если слово имеет одно значение и не образует в сочетании с другими словами сложных слов, что может запутать обучающихся. После иллюстративного знакомства с возможностями лингвистического корпуса, школьники приступают к изучению теоретической формулировки правил английского языка в учебниках и словарях, целью которого является закрепления знаний о значении слова и возможностях словоупотребления в английском языке.

2) Определение особенностей лексической сочетаемости слов. Задания:

- используя корпусные данные сравните возможности употребления глаголов take и make с существительными (функция Compare);

- определите, какие прилагательные чаще всего употребляются с существительными man и woman в художественных и публицистических текстах, и т.д.

3) Поиск синонимов. Задания:

- сравните употребление синонимичных прилагательных fast и rapid с существительными;

- изучите сочетаемость синонимичных глаголов build и construct с существительными, обозначающими объект строительства;

- сравните употребление существительных со значением снижения/падения в устной речи и научном подкорпусе и т.д.

4) Составление тематических списков ключевых слов. Задания:
- составьте списки наиболее частотных прилагательных, употребляемых в религиозных и развлекательных журналах (в сравнении);

- составьте список существительных, наиболее часто употребляемых в научных журналах по медицине и т.д.

\section{5) Поиск иллюстративного материала.}

На старшей ступени обучения возможно коллективное составление учащимися собственных корпусов текстов, позволяющих наглядно проиллюстрировать особенности лексического значения того или иного слова. Интересным приемом будет использование сопоставительного анализа английских контекстов словоупотребления и вариантов функционирования слова в контекстах русского языка.

\section{Зак^ючение}

В процессе работы с теоретическими источниками было установлено, что новая образовательная парадигма требует поиска новых подходов в обучении иностранным языкам, одними из которых являются «корпусные технологии». К преимуществам корпусного подхода, с точки зрения современной лингводидактики, относятся: лингвистическая и статистическая наглядность; широкие поисковые возможности; эффективность работы с реальными языковыми данными. Особенность корпусного подхода состоит в возможности оперативного поиска языкового материала, необходимого для решения тех или иных образовательных задач в процессе обучения иностранному языку.

Согласно результатам исследования среди приоритетных задач обучения лексике английского языка в средних классах, эффективное решение которых становится возможным благодаря применению корпусного подхода, можно выделить:

- расширение лексического запаса учащихся;

- становление умений определения лексической сочетаемости слов с целью преодоления речевых и стилистических ошибок;

- развитие речи посредством составления тематических списков ключевых слов и т.д.

Таким образом, метод лингвистического исследования, основанный на корпусах текстов, дает возможность учителю свободно применять проблемно-поисковый подход в преподавании и гарантирует появление интереса у школьников, так как они становятся своего рода «первооткрывателями» неизвестных им лингвистических явлений английского языка, что соответствует требованиям нового образовательного стандарта. 


\section{ЛИТЕРАТУРА}

1. Федеральный государственный образовательный стандарт среднего общего образования (утв. приказом Министерства образования и науки РФ от 17 мая 2012 г. N 413). ( изменениями и дополнениями от: 29 декабря 2014 г., 31 декабря 2015 г., 29 июня 2017 г., 24 сентября, 11 декабря 2020 г. - [Электронный ресурс] / - URL: https://base.garant.ru/70188902/8ef641d3b80ff01d34be16ce9bafc6e0/

2. Багдасарова Э.В. Глагольная лексика в современном английском языке: этимологический, словообразовательный и семантический аспекты [Электронный ресурс] / Э.В. Багдасарова - URL: http://www.lib.ua-ru.net/diss/cont/210514.html (дата обращения 17.09.2021).

3. Горина 0.Г. Использование технологий корпусной лингвистики для развития лексических навыков студентов-регионоведов в профессионально-ориентированном общении на английском языке [Электронный ресурс] / 0.Г. Горина - URL: http://www.dslib.net/teoria-vospitania/gorina-ispolzovanietehnologij-korpusnoj-lingvistiki-dlja-razvitija-leksicheskih-navykov.html (дата обращения 16.09.2021).

4. Захаров В.П., Богданова С.Ю. Корпусная лингвистика: учебник / В.П. Захаров, С.Ю. Богданова - Издательство Иркутского государственного лингвистического университета, 2014 г. - 161 с.

5. Павловская И.Ю., Горина О.Г. Корпусно-когнитивные методы изучения лексической стороны речи на иностранном языке / И.Ю. Павловская, О.Г. горина // Вестник Череповецкого государственного университета. - 2017. - №1. - С. 132-138.

6. Плунгян В.А. Почему современная лингвистика должна быть лингвистикой корпусов [Электронный ресурс] / B.A. Плунгян - URL: http://filolingvia.com/ publ/pochemu_sovremennaja_lingvistika_dolzhna_byt_lingvistikoj_korpusov/70-1-0-5251 (дата обращения 16.09.2021).

7. Рыков В.В. Корпусная лингвистика и лексикография - проблема репрезентативности / В.В. Рыков // Труды Конференции по лексикографии - Гродно, 2013 г. -148 c.

8. Соснина Е.П. Корпусная лингвистика и корпусный подход в обучении иностранному языку [Электронный ресурс] / E.П. Cocнина - URL: http://ling.ulstu.ru/ linguistics/resourses/literature/articles/corpus_linguistics_language_teaching/ (дата обращения 17.09.2021).

9. Сысоев П.В. Лингвистический корпус в методике обучения иностранным языкам. [Электронный ресурс]. / П.В. Сыcoeв - URL: https://cyberleninka.ru/ article/n/lingvisticheskiy-korpusv-metodike-obucheniya-inostrannym-yazykam/viewer

10. Шаламова Н.Н., Фильченко, А.Ю. Корпусная лингвистика и её использование в профильно-ориентированном преподавании иностранных языков. / Н.Н. Шаламова, А.Ю. Фильченко - Томск: ТПУ, - 2014 - 164 с.

11. Bestgen Y. Comparing Lexical Bundles across Corpora of Different Sizes: The Zipfian Problem. // Journal of Quantitative Linguistics, 2020, vol. 27, no. 3, - p. 272-290.

12. Lewis M. Implementing the lexical approach: Putting theory into practice. Heinlecengage, $2018-223 \mathrm{p}$.

13. Salazar D. Lexical Bundles in Native and Non-native Scientific Writing: Applying a corpus based study to language teaching. Amsterdam, Phil., John Benjamins Publishing Company, $2019-212 \mathrm{p}$.

14. Scott M., Tribble C. Textual Patterns: key words and corpus analysis in language education: Studies in Corpus Linguistics. Amsterdam, Philadelphia, John Benjamins, $2016-200 p$.

( ) Низамеева Альбина Марсилевна (albina10091976@mail.ru). 